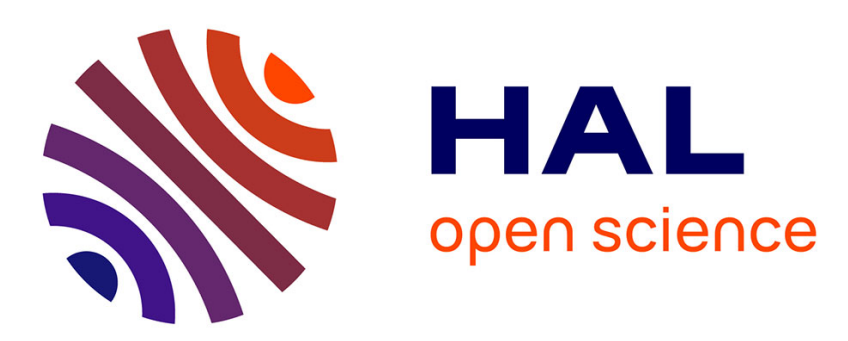

\title{
A simple device for determining thermal effusivity of thin plates
}

Elian Coment, Jean-Christophe Batsale, Bruno Ladevie, Jean-Luc Battaglia

\section{To cite this version:}

Elian Coment, Jean-Christophe Batsale, Bruno Ladevie, Jean-Luc Battaglia. A simple device for determining thermal effusivity of thin plates. High Temperatures-High Pressures, 2002, 34 (6), pp.627 - 637. hal-01651381

\section{HAL Id: hal-01651381 https://imt-mines-albi.hal.science/hal-01651381}

Submitted on 7 Nov 2019

HAL is a multi-disciplinary open access archive for the deposit and dissemination of scientific research documents, whether they are published or not. The documents may come from teaching and research institutions in France or abroad, or from public or private research centers.
L'archive ouverte pluridisciplinaire HAL, est destinée au dépôt et à la diffusion de documents scientifiques de niveau recherche, publiés ou non, émanant des établissements d'enseignement et de recherche français ou étrangers, des laboratoires publics ou privés. 


\title{
A simple device for determining thermal effusivity of thin plates
}

\author{
Elian Coment, Jean-Christophe Batsale $\uparrow$, Bruno Ladevie, Jean-Luc Battaglia $\uparrow$ \\ Centre Énergétique Environnement, LGPSD, UMR 2392 CNRS, École des Mines d'Albi, Campus Jarlard, \\ F-81013 Albi Cedex 09, France \\ - Laboratoire Énergétique et Phénomènes de Transfert, UMR CNRS-Bx1-ENSAM8508, École Nationale \\ Supérieure d'Arts et Métiers, Esplanade des Arts et Métiers, F-33405 Talence Cedex, France; \\ email: coment@enstimac.fr \\ Presented at the 16th European Conference on Thermophysical Properties, Imperial College, London, \\ England, 1-4 September 2002
}

\begin{abstract}
We measured thermal effusivity of thin plates in the longitudinal direction. This parameter is strongly correlated with lateral convection, so its determination is very difficult. Thermal quadrupole theory is presented which allows the theoretical expression of the problem to be determined. By applying a heat flux without a low-frequency component, only some characteristic times of the system are excited. A real-time method of estimation is developed by using a non-integer derivative signal. The results obtained for a copper plate are in good agreement with the literature.
\end{abstract}

\section{Nomenclature}

\begin{tabular}{|c|c|c|}
\hline Symbol & Quantity & Units \\
\hline$a$ & thermal diffusivity & $\mathrm{m}^{2} \mathrm{~s}^{-1}$ \\
\hline$C_{n}$ & specific heat & $\mathrm{J} \mathrm{kg}^{-1} \mathrm{~K}^{-1}$ \\
\hline $\mathrm{D}^{n}$ & non-integer derivative operator & \\
\hline$e$ & thickness & $\mathrm{m}$ \\
\hline$f$ & frequency & $\mathrm{Hz}$ \\
\hline$h$ & convection heat transfer coefficient & 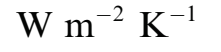 \\
\hline$H$ & transfer function & \\
\hline$L$ & Laplace transform & \\
\hline$p$ & Laplace variable & \\
\hline$R$ & contact resistance & $\mathrm{m}^{2} \mathrm{~W}^{-1} \mathrm{~K}^{-1}$ \\
\hline$t$ & time & $\mathrm{s}$ \\
\hline$T$ & temperature & $\mathrm{K}$ \\
\hline$x, y$ & coordinates & \\
\hline$Z$ & thermal impedance & \\
\hline$\alpha, \beta$ & parameters & \\
\hline$\Delta$ & sampling & \\
\hline$\varepsilon$ & residues & \\
\hline$\xi$ & error modelling & \\
\hline$\zeta$ & measurement noise & \\
\hline$\lambda$ & thermal conductivity & $\mathrm{W} \mathrm{m}^{-1} \mathrm{~K}^{-1}$ \\
\hline$\phi$ & heat flux density & $\mathrm{W} \mathrm{m}^{-2}$ \\
\hline$\Phi$ & Laplace transform of heat flux density & \\
\hline$\rho$ & density & $\mathrm{kg} \mathrm{m}^{-3}$ \\
\hline$\theta$ & Laplace transform of temperature & \\
\hline$\omega$ & rate of pulsation & $\mathrm{rad} \mathrm{s}^{-1}$ \\
\hline \multicolumn{3}{|l|}{ Subscripts } \\
\hline M & plate medium & \\
\hline $\mathrm{s}$ & sensor & \\
\hline $\mathrm{f}$ & filtered & \\
\hline \multicolumn{3}{|l|}{ Superscripts } \\
\hline & estimated magnitudes & \\
\hline * & magnitudes with noise & \\
\hline
\end{tabular}




\section{Introduction}

Estimation of thermal properties of thin plates in longitudinal direction is an important problem in thermal science. It is needed in many industrial applications, such as control of fuel tanks in aircraft, tanks in boats and alimentary industries, characterisation of orthotropic composite plates, and study of conductive coatings on an insulating material. In order to provide an easy experimental method of determining thermal effusivity, a simple device was developed.

Many theoretical and experimental studies have been carried out on thermal transfer in plates. The plates may be thin or thick, insulating or conducting, fixed or moving; all studies deal with the geometry, type of excitation, and thermal measurement devices.

Among these methods, measurement of thermal diffusivity of thin plates is thought by us to be particularly similar to this study. According to a bibliographic search, three sorts of configuration can be identified. First, stack plates were studied by Katayama et al (1969), and Zhang and Degiovanni (1993). Next, heat transfer across the thickness of a plate has been measured by the flash method (see Parker et al 1961; Degiovanni and Laurent 1986) and by the periodical flux method (Skumanich et al 1987). Finally, methods of determining the longitudinal heat transfer in plates have been developed (Degiovanni et al 1990; Hadisaroyo et al 1992; Philippi 1994).

We studied longitudinal heat transfer in thin metallic plates. Because of lateral heat loss, our problem is that of a semi-infinite plate in transient state. The disturbances generated by the sensor are not neglected; they are modelled by a resistance and localised capacities introduced into the model. A sensitivity study was carried out to establish the accessible parameters and the optimal frequency range.

After describing the experimental device and the principle of the method, we present a mathematical model and its application to thermal effusivity. Finally, we report our first experimental results.

\section{The experimental device and the principle of the method}

The experimental device is shown in figure 1. Heat flux $\phi(t)$ is applied to the surface of the material and the temperature $T(t)$ is measured with a thin-strip sensor consisting of a Joule effect reheater and a type $\mathrm{K}$ thermocouple. The thermocouple is placed in the central zone of the system. The plate is long enough to be assumed to be semi-infinite.

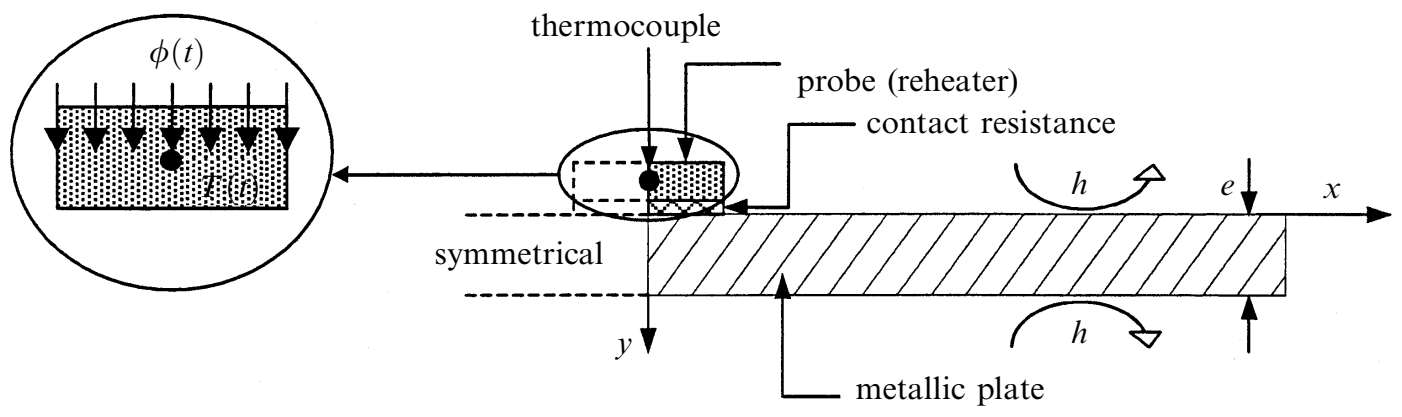

Figure 1. Experimental device.

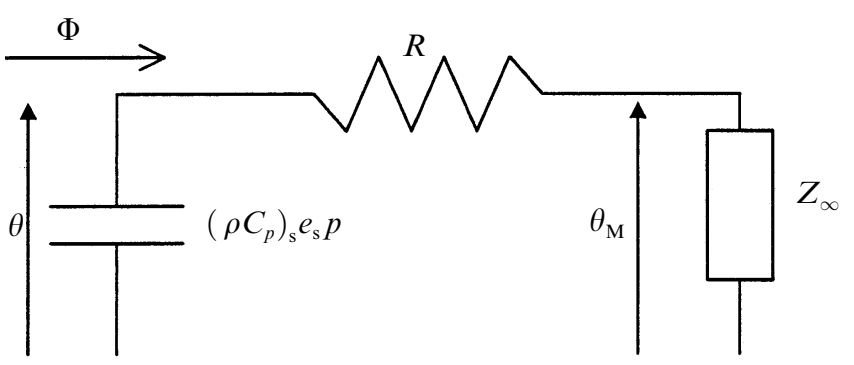

Figure 2. Modelling by means of an electrical analogy. 
This device represents a thermal system, which can be modelled with an electrical analogy shown in figure 2 .

\section{Theoretical aspect}

The characteristics of the plate (high conductivity and small thickness) allow us to reduce the problem to unidirectional heat transfer in the longitudinal direction $x$. Therefore, the 2-D problem (figure 1) becomes equivalent to a 1-D problem (figure 3).

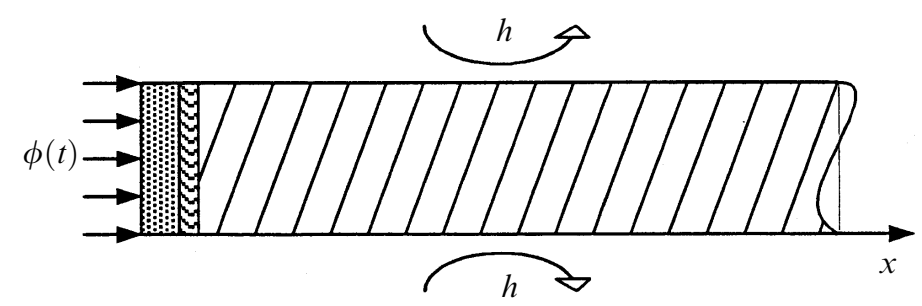

Figure 3. Schematic representation of an equivalent 1-D problem.

\subsection{Transfer function}

The sensor is very thin and assumed to be isothermal. The contact between the sample plate and the sensor introduces a resistance $R$ at the interface. The entire device is subject to lateral heat loss and therefore treated as a semi-infinite plate in transient state. The well-known formalism of the thermal quadrupole (Maillet et al 2000) leads then in terms of the Laplace field to an input/output relation of the type:

$$
\left[\begin{array}{l}
\theta(p) \\
\Phi(p)
\end{array}\right]=\left[\begin{array}{cc}
1 & 0 \\
\left(\rho C_{p}\right)_{\mathrm{s}} e_{\mathrm{s}} p & 1
\end{array}\right]\left[\begin{array}{cc}
1 & R \\
0 & 1
\end{array}\right]\left[\begin{array}{c}
\theta_{\mathrm{M}} \\
\left(\lambda \rho C_{p}\right)^{1 / 2}\left[p+k \theta_{\mathrm{M}}(p)\right]^{1 / 2}
\end{array}\right],
$$

where $k=2 h a / \lambda e, \theta(p)=L[T(t)], \Phi(p)=L[\phi(t)]$, and $\theta_{\mathrm{M}}(p)=L\left[T_{\mathrm{M}}(t)\right]$.

Therefore, the model describing the measurement of temperature as a function of heat flux density in terms of the Laplace has the form:

$$
\theta(p)=\frac{1+R\left(\lambda \rho C_{p}\right)^{1 / 2}(p+k)^{1 / 2}}{\left(\rho C_{p}\right)_{\mathrm{s}} e_{\mathrm{s}} p+\left(\lambda \rho C_{p}\right)^{1 / 2}(p+k)^{1 / 2}\left[R\left(\rho C_{p}\right)_{\mathrm{s}} e_{\mathrm{s}} p+1\right]} \Phi(p)=H(p) \Phi(p),
$$

where $H(p)$ is the transfer function.

\subsection{Sensitivity study}

By analogy, relation (2) can be written in terms of the Fourier field $(p=\mathrm{j} \omega)$. Here the transfer function becomes a complex function $H(\mathrm{j} \omega)$. In the symmetrical system we are considering here, we have four variables. On the one hand, there are the characteristics of the material-effusivity $\left(\lambda \rho C_{p}\right)^{1 / 2}$ and lateral heat loss $k$; and on the other hand, a parameter related to metrology - the contact resistance $R$ - and sensor capacity $\left(\rho C_{p}\right)_{\mathrm{s}} e_{\mathrm{s}}$. The effusivity of material is here the required quantity. A sensitivity study allows us to discuss the possibility of simultaneous determination of the parameters. This analysis evaluates sensitivity to the parameters and checks the conditions of decorrelation of the quantities. It also allows us to optimise the frequency window according to the required objectives. It can lead in the last resort to a reduction of the model if it is shown that in the observation window certain parameters have a negligible role.

With the function $H(\mathrm{j} \omega)$ being a complex function of frequency, we chose to study the sensitivities of both the modulus and the phase to the various parameters. The sensitivity functions of the modulus and the phase of the tested function $\Omega$ to parameter $\eta_{i}$ are defined by the relation:

$$
X_{\eta_{i}}(f)=\frac{1}{\Omega\left(\eta_{1}, \eta_{2}, \cdots, \eta_{n}, f\right)} \eta_{i} \frac{\delta \Omega\left(\eta_{1}, \eta_{2}, \cdots, \eta_{n}, f\right)}{\delta \eta_{i}},
$$




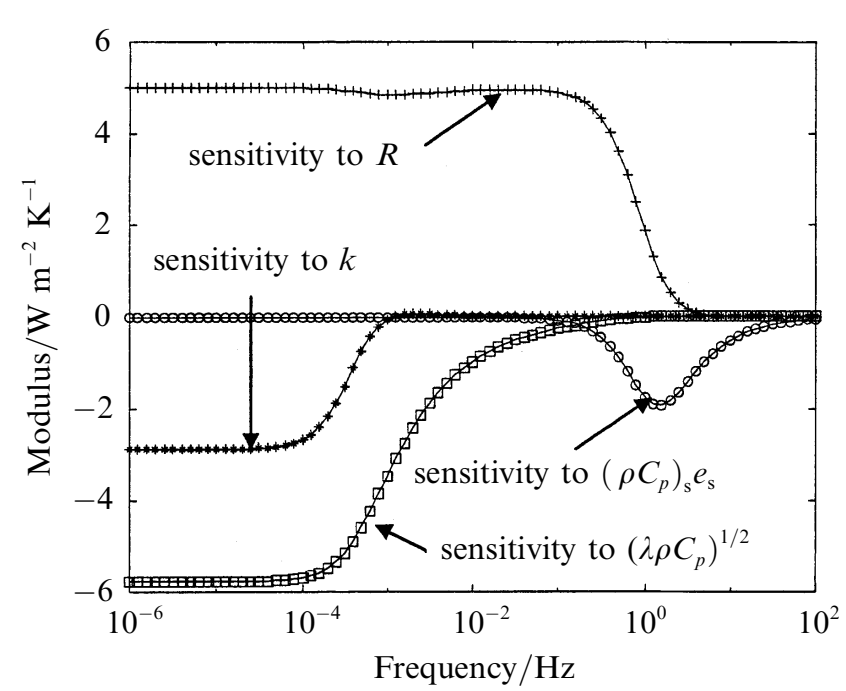

Figure 4. Sensitivity of the modulus of $H$ to various parameters as a function of frequency.

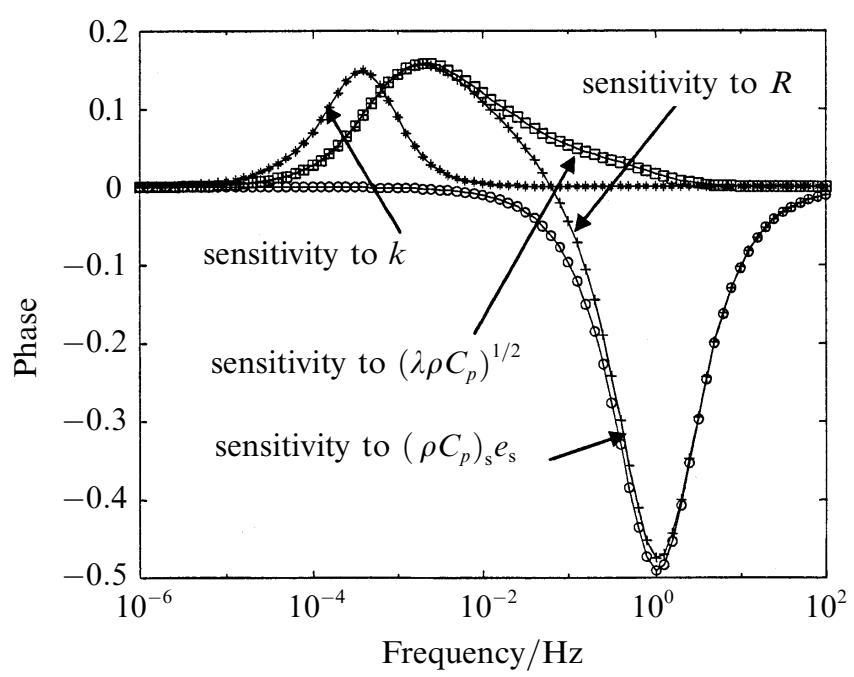

Figure 5. Sensitivity of the phase of $H$ to various parameters as a function of frequency.

where $f=\omega / 2 \pi$. In expression (3), $\Omega$ represents in turn the modulus of $H$, and the phase of $H$. The sensitivities are defined by the ratio of the variations of the tested function to relative variations of the parameters. We show in figures 4 and 5 the results covering the frequency range $10^{-6} \mathrm{~Hz}$ to $10^{2} \mathrm{~Hz}$.

To carry out these calculations, some orders of magnitude of the expected values of the parameters are injected into the model. They are average values obtained from the literature. In the frequency window $10^{-6} \mathrm{~Hz}$ to $10^{-3} \mathrm{~Hz}$, the sensitivities of the modulus to the effusivity and lateral heat loss remain high, but unfortunately follow a similar pattern, and so seem to be correlated. On the other hand, at high frequencies, only sensor characteristics are sensitive. However, for the frequency range $10^{-2} \mathrm{~Hz}$ to $10^{2} \mathrm{~Hz}$, the sensitivity of the modulus and phase to $k$ is null, so this parameter can be neglected in this frequency range. This indicates that the material should be excited in this frequency range. The reduced model requires finally three unknown parameters to be determined simultaneously.

\section{Determination of parameters by a fractional model}

\subsection{Structure of the identification model}

A non-integer identification model is used in an inverse method to determine the unknown parameters (see Oustaloup 1995; Battaglia et al 2000). Indeed, relation (4) 
shows that we have to derive the physical parameters of our system-both the temperature and the heat flux - in a non-integer form:

$$
\left(\alpha_{1} p^{0.5}+\alpha_{2} p+\alpha_{3} p^{1.5}\right) \theta(p)=\left(\beta_{1}+\beta_{2} p^{0.5}\right) \Phi(p),
$$

where $\alpha_{1}=1, \quad \alpha_{2}=\left(\rho C_{p}\right)_{\mathrm{s}} e_{\mathrm{s}} /\left(\lambda \rho C_{p}\right)^{1 / 2}, \quad \alpha_{3}=R\left(\rho C_{p}\right)_{\mathrm{s}} e_{\mathrm{s}}, \quad \beta_{1}=\left(\lambda \rho C_{p}\right)^{-1 / 2}, \quad \beta_{2}=R$. The fractional differential equation is of the form

$$
\alpha_{1} \mathrm{D}^{0.5} T(t)+\alpha_{2} \mathrm{D}^{1} T(t)+\alpha_{3} \mathrm{D}^{1.5} T(t)=\beta_{1} \phi(t)+\beta_{2} \mathrm{D}^{0.5} \phi(t) .
$$

The general non-integer derivative of a function $g(t)$ is written with the use of the discrete definition of Grünwald (see Miller and Ross 1993):

$$
D^{n} g(t)=\frac{1}{\Delta t^{n}} \sum_{k=0}^{K}(-1)^{k}\left(\begin{array}{l}
n \\
k
\end{array}\right) g(t-k \Delta t), \quad n \in \Re, \quad t=K \Delta t,
$$

where

$$
\left(\begin{array}{l}
n \\
k
\end{array}\right)=\frac{n(n-1) \cdots(n-k+1)}{k !}
$$

is Newton's binomial and $\Delta t$ assigns the sampling.

The goal of the identification is to estimate, from observed data (temperature and heat flux) of the system to be studied (figure 1), the coefficients of the fractional differential equation (5). Here, this model is characterised by the vector $\boldsymbol{\vartheta}=\left[\begin{array}{llll}\alpha_{2} & \alpha_{3} & \beta_{1} & \beta_{2}\end{array}\right]^{T}$.

Applying a linear transformation [low-pass filter $F(p)$ in our case] to equation (5) and isolating $\mathrm{D}^{0.5} T_{\mathrm{f}}(t)$, we obtain a linear continuous regression with null initial conditions, of the form:

$$
\begin{aligned}
\mathrm{D}^{0.5} T_{\mathrm{f}}(t) & =-\alpha_{2} \mathrm{D}^{1} T_{\mathrm{f}}(t)-\alpha_{3} \mathrm{D}^{1.5} T_{\mathrm{f}}(t)+\beta_{1} \mathrm{D}^{0} \phi_{\mathrm{f}}(t)+\beta_{2} \mathrm{D}^{0.5} \phi_{\mathrm{f}}(t) \\
& =\left[\begin{array}{llll}
-\mathrm{D}^{1} T_{\mathrm{f}}(t) & \mathrm{D}^{1.5} T_{\mathrm{f}}(t) & \mathrm{D}^{0} \phi_{\mathrm{f}}(t) & \mathrm{D}^{0.5} \phi_{\mathrm{f}}(t)
\end{array}\right] \boldsymbol{\vartheta} \\
& =\boldsymbol{\varphi}_{\mathrm{f}} \boldsymbol{\vartheta},
\end{aligned}
$$

where $T_{\mathrm{f}}(t)$ and $\phi_{\mathrm{f}}(t)$ are, respectively, the filtered temperature and the heat flux. Even though equations (5) and (7) are equivalent, only the form of equation (7) allows us to compute the various derivatives from observed data.

\subsection{Fractional state-variable-filter design}

In order to estimate parameters, the fractional derivatives of the filtered data $T_{\mathrm{f}}(t)$ and $\phi_{\mathrm{f}}(t)$, included in the vector $\boldsymbol{\varphi}_{\mathrm{f}}$, require to be computed. Indeed, computation of fractional derivatives with the use of approximation (6) generates significant errors. The method consists of using a fractional state-variable-filter (SVF), which is composed of the fractional derivatives of the filtered data:

$$
\boldsymbol{x}=\left[\mathrm{D}^{\left(N_{\mathrm{f}}-1\right) \times n} z_{\mathrm{f}}(t), \mathrm{D}^{\left(N_{\mathrm{f}}-2\right) \times n} z_{\mathrm{f}}(t), \ldots, \mathrm{D}^{n} z_{\mathrm{f}}(t), z_{\mathrm{f}}(t)\right]^{T},
$$

where $z_{\mathrm{f}}(t)$ denotes either $T_{\mathrm{f}}(t)$ or $\phi_{\mathrm{f}}(t) ; n=0.5$, and $N_{\mathrm{f}} \in$.

The state-variable-filter used here results from an extension of the Poisson filter to fractional systems:

$$
F(p)=\left[\left(\frac{p}{\omega_{\mathrm{f}}}\right)^{n}+1\right]^{-N_{\mathrm{f}}}=\frac{\omega_{\mathrm{f}}^{n \times N_{\mathrm{f}}}}{p^{n \times N_{\mathrm{f}}}+\mathrm{C}_{1}^{N_{\mathrm{f}}} \omega_{\mathrm{f}}^{n} p^{n \times\left(N_{\mathrm{f}}-1\right)}+\ldots+\mathrm{C}_{N_{\mathrm{f}}-1}^{N_{\mathrm{f}}} \omega_{\mathrm{f}}^{n \times\left(N_{\mathrm{f}}-1\right)} p^{n}+\omega_{\mathrm{f}}^{n \times N_{\mathrm{f}}}},
$$

where $\omega_{\mathrm{f}}$ is the characteristic pulsation frequency of the system, and the filter order is defined by $n \times N_{\mathrm{f}}$. 
The fractional state-space representation of the filter can be written down in the form:

$$
\mathrm{D}^{n} \boldsymbol{x}(t)=\left[\begin{array}{ccccc}
-\mathrm{C}_{1}^{N_{\mathrm{f}}} \omega_{\mathrm{f}}^{n} & -\mathrm{C}_{2}^{N_{\mathrm{f}}} \omega_{\mathrm{f}}^{2 \times n} & \ldots & \mathrm{C}_{N_{\mathrm{f}}-1}^{N_{\mathrm{f}}} \omega_{\mathrm{f}}^{n \times\left(N_{\mathrm{f}}-1\right)} & \omega_{\mathrm{f}}^{n \times N_{\mathrm{f}}} \\
1 & 0 & \ldots & \ldots & 0 \\
0 & \ddots & 0 & & \vdots \\
\vdots & \ddots & \ddots & \ddots & \vdots \\
0 & \ldots & 0 & 1 & 0
\end{array}\right] \boldsymbol{x}(t)+\left[\begin{array}{c}
\omega_{\mathrm{f}}^{n \times N_{\mathrm{f}}} \\
0 \\
\vdots \\
\vdots \\
0
\end{array}\right] z(t)
$$

By using Grünwald approximation (6), the filter can be simulated and the fractional derivatives of the filtered data directly obtained.

\subsection{Parameter estimation}

Let us consider a $K$ pair of observed data $T^{*}(t)$ and $\phi(t)$ with

$$
T^{*}(t)=T(t)+\zeta(t),
$$

where $\zeta(t)$ is the perturbation signal (measurement noise).

The identification problem can be solved by using a linear least-squares technique (see Ljung 1987), by minimising the quadratic norm of function $\varepsilon(t)$ defined by:

$$
\begin{aligned}
\varepsilon(t) & =\mathrm{D}^{0.5} T_{\mathrm{f}}^{*}(t)+\hat{\alpha}_{2} \mathrm{D}^{1} T_{\mathrm{f}}^{*}(t)+\hat{\alpha}_{3} \mathrm{D}^{1.5} T_{\mathrm{f}}^{*}(t)-\hat{\beta}_{1} \mathrm{D}^{0} \phi_{\mathrm{f}}(t)-\hat{\beta}_{2} \mathrm{D}^{0.5} \phi_{\mathrm{f}}(t) \\
& =\boldsymbol{\varphi}_{\mathrm{f}}^{*} \hat{\boldsymbol{\vartheta}},
\end{aligned}
$$

where $\hat{\vartheta}=\left[\begin{array}{llll}\hat{\alpha}_{2} & \hat{\alpha}_{3} & \hat{\beta}_{1} & \hat{\beta}_{2}\end{array}\right]^{T}$ is the vector of parameters to be estimated.

The criterion $J$ that we need to minimise can be written:

$$
J(\hat{\boldsymbol{\vartheta}})=\boldsymbol{E}^{T} \boldsymbol{E}
$$

where $\boldsymbol{E}=\left[\begin{array}{lll}\varepsilon\left(\kappa_{0} \Delta t\right) & \varepsilon\left\{\left(\kappa_{0}+1\right) \Delta t\right\} \ldots \varepsilon\left\{\left(\kappa_{0}+K-1\right) \Delta t\right\}\end{array}\right]^{T}, \kappa_{0}$ is an integer chosen such that $\kappa_{0} \Delta t \geq t_{\mathrm{f}}$, where $t_{\mathrm{f}}$ denotes the settling time of the filter $F(p)$. $J(\hat{\vartheta})$ :

Using the linear regression form (7), we obtain the optimal value of $\hat{\vartheta}$ minimising

$$
\hat{\boldsymbol{\vartheta}}_{\text {opt }}=\left(\boldsymbol{X}_{\mathrm{f}}^{* T} \boldsymbol{X}_{\mathrm{f}}^{*}\right)^{-1} \boldsymbol{X}_{\mathrm{f}}^{* T} \mathrm{D}^{0.5} T_{\mathrm{f}}^{*},
$$

where

$$
\left\{\begin{array}{ll}
\boldsymbol{X}_{\mathrm{f}}^{*}=\left[\begin{array}{lll}
\boldsymbol{\varphi}_{\mathrm{f}}^{* T}\left(\kappa_{0} \Delta t\right) & \boldsymbol{\varphi}_{\mathrm{f}}^{* T}\left\{\left(\kappa_{0}+1\right) \Delta t\right\} \ldots \boldsymbol{\varphi}_{\mathrm{f}}^{* T}\left\{\left(\kappa_{0}+K-1\right) \Delta t\right\}
\end{array}\right]^{T} \\
\boldsymbol{T}_{\mathrm{f}}^{*}=T_{\mathrm{f}}^{*}\left(\kappa_{0} \Delta t\right) & \left.T_{\mathrm{f}}^{*}\left\{\left(\kappa_{0}+1\right) \Delta t\right\} \ldots T_{\mathrm{f}}^{*}\left\{\left(\kappa_{0}+K-1\right) \Delta t\right\}\right]^{T}
\end{array} .\right.
$$

\subsection{Analysis of the estimation bias}

In order to analyse the estimation bias, we consider a signal $\xi(t)$ defined by

$$
\xi(t)=L^{-1}\left\{\left(p^{0.5}+\alpha_{2} p+\alpha_{3} p^{1.5}\right) \times F(p)\right\} \otimes \zeta(t),
$$

where $L^{-1}$ denotes the inverse Laplace transform and $\otimes$ the convolution product. Combining equations (5) and (15), we obtain:

$$
\mathrm{D}^{0.5} T_{\mathrm{f}}^{*}(t)+\alpha_{2} \mathrm{D}^{1} T_{\mathrm{f}}^{*}(t)+\alpha_{3} \mathrm{D}^{1.5} T_{\mathrm{f}}^{*}(t)=\beta_{1} \mathrm{D}^{0} \phi_{\mathrm{f}}(t)+\beta_{2} \mathrm{D}^{0.5} \phi_{\mathrm{f}}(t)+\xi(t) .
$$

Relation (16) can be written in matrix form:

$$
\mathrm{D}^{0.5} \boldsymbol{T}_{\mathrm{f}}^{*}=\boldsymbol{X}_{\mathrm{f}}^{*} \boldsymbol{\vartheta}+\boldsymbol{\xi} .
$$

The classical estimation bias can be deduced by replacing $\mathrm{D}^{0.5} \boldsymbol{T}_{\mathrm{f}}{ }^{*}$ in equation (14) by its expression (17):

$$
\Delta \boldsymbol{\vartheta}=\hat{\boldsymbol{\vartheta}}_{\mathrm{opt}}-\boldsymbol{\vartheta}=\left(\boldsymbol{X}_{\mathrm{f}}^{* T} \boldsymbol{X}_{\mathrm{f}}^{*}\right)^{-1} \boldsymbol{X}_{\mathrm{f}}^{* T} \boldsymbol{\xi}
$$

where $\xi=\left[\begin{array}{lll}\xi\left(\kappa_{0} \times \Delta t\right) & \xi\left\{\left(\kappa_{0}+1\right) \times \Delta t\right\} \ldots \xi\left\{\left(\kappa_{0}+K-1\right) \times \Delta t\right\}\end{array}\right]^{T}$. 


\section{Results and discussion}

A sensor placed in the central zone of the investigated plate constitutes the experimental device (figure 1). This sensor comprises both a reheater strip and a Chromel-Alumel thermocouple situated in the middle of the strip. The total thickness of the sensor is approximately $0.2 \mathrm{~mm}$. The reheater is fed from an amplified signal generator. The delivered power of the excitation is measured and therefore well known. The two thermocouple wires are connected to brass pins kept at ambient temperature. The thermocouple output is amplified 1000 times. A numerical oscilloscope ensures acquisition of the data. In order to improve the contact between the sensor and the plate, we used a thermal tape. The plate size $(500 \mathrm{~mm} \times 100 \mathrm{~mm} \times 2 \mathrm{~mm})$ is sufficient for the material to be regarded as a semi-infinite medium with respect to thermocouple for an acquisition time of about $80 \mathrm{~s}$.

An excitation without a low-frequency component is used so as to make it insensitive to lateral heat loss. Therefore, the permanent component of the excitation $\phi(t)$ must also be zero. In practice, two experiments are simultaneously carried out. First, we store the temperature signal obtained at a heat flux density in the form of a sequence of square waves. Next, a similar experiment is carried out with a Heaviside heat flux density half the previous one. By deducting the second signal from the first we obtain the required results (see figure 6). The same procedure is applied to the temperature $T(t)$.

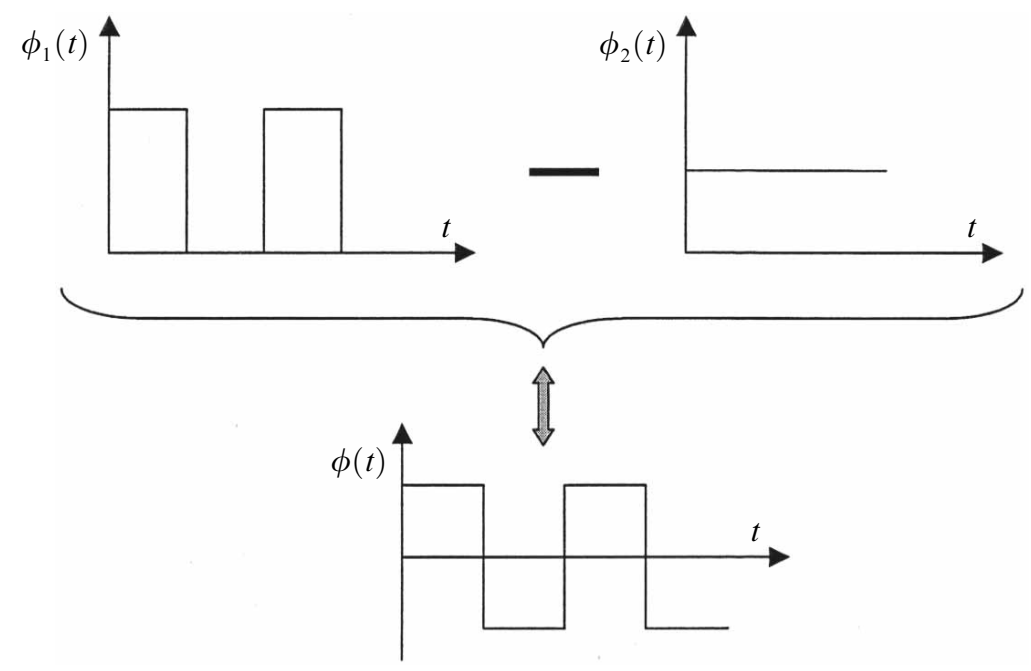

Figure 6. Schematic description of the experimental method.

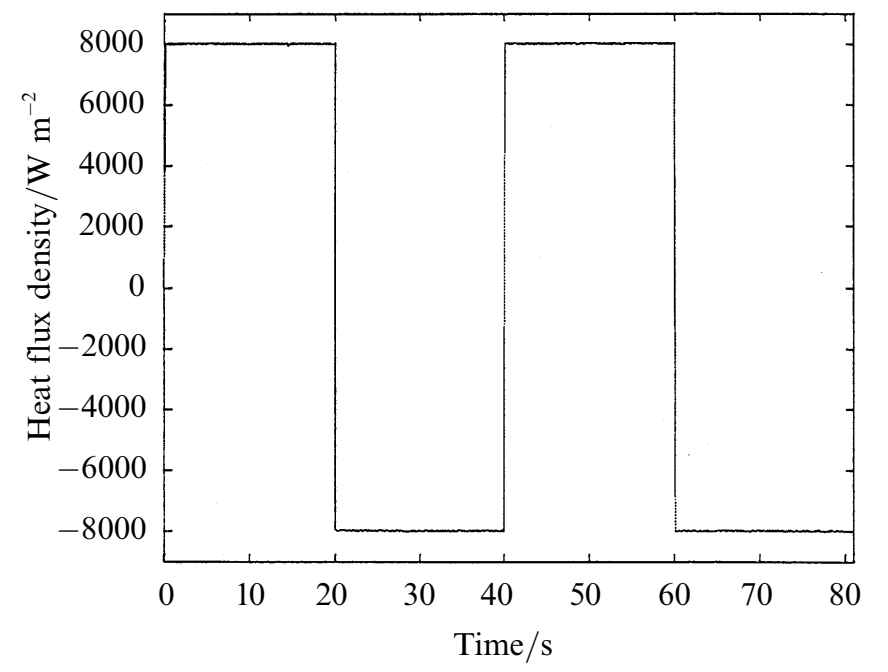

Figure 7. Experimental heat flux density as a function of time. 


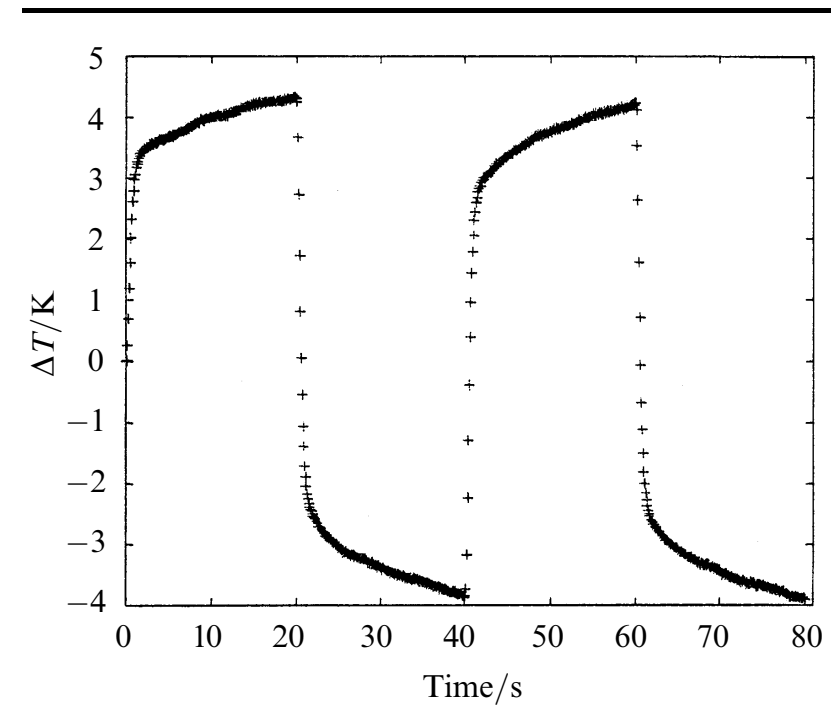

Figure 8. Variation of temperature with time.

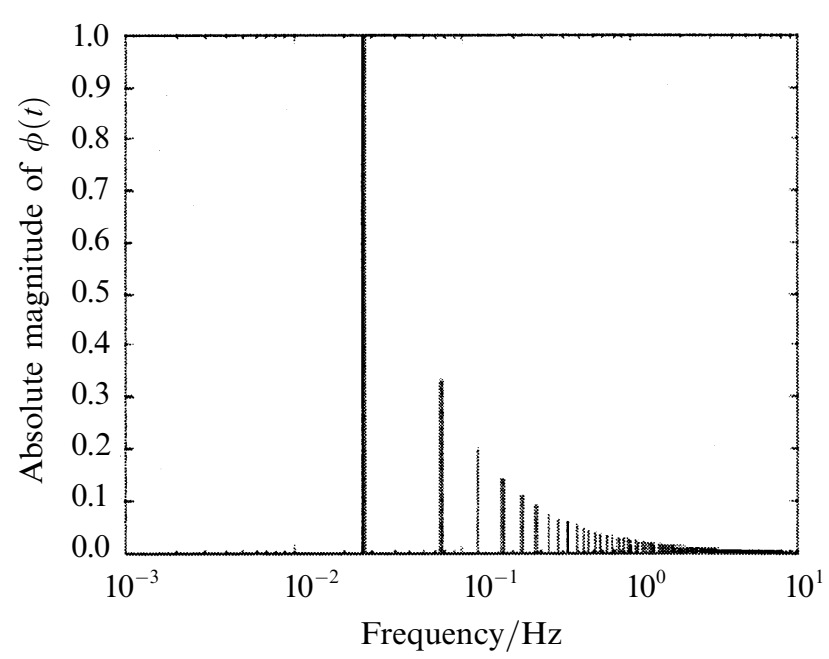

Figure 9. Spectral analysis of $\phi(t)$.

Table 1. Parameters obtained from the response to the heat flux $(\Delta t=0.1 \mathrm{~s})$.

Derivative order Differential model parameters

$$
\begin{array}{ll}
\boldsymbol{n}_{\alpha}=\left[\begin{array}{c}
0.5 \\
1 \\
1.5
\end{array}\right] & \boldsymbol{\alpha}=\left[\begin{array}{c}
1 \\
-0.3732 \\
0.5721
\end{array}\right] \\
\boldsymbol{n}_{\beta}=\left[\begin{array}{c}
0 \\
0.5
\end{array}\right] & \boldsymbol{\beta}=\left[\begin{array}{l}
4.65 \times 10^{-5} \\
3.07 \times 10^{-4}
\end{array}\right]
\end{array}
$$

The method described here was applied to determine the thermal effusivity of a copper plate. The generalised magnitudes of heat flux density and temperature thus obtained are represented in figures 7 and 8 as functions of time. A spectral analysis of the function $\phi(t)$ (figure 9) is presented to draw attention to the frequency field used for the test. It shows that the intended frequency range is well covered. Indeed, this signal permits us to filter out low frequencies so as to eliminate the lateral heat loss. The values of the parameters calculated by equation (14) with data obtained from this test are listed in table 1 . A sampling period $\Delta t$ of $0.1 \mathrm{~s}$ was chosen to compute the parameters. 


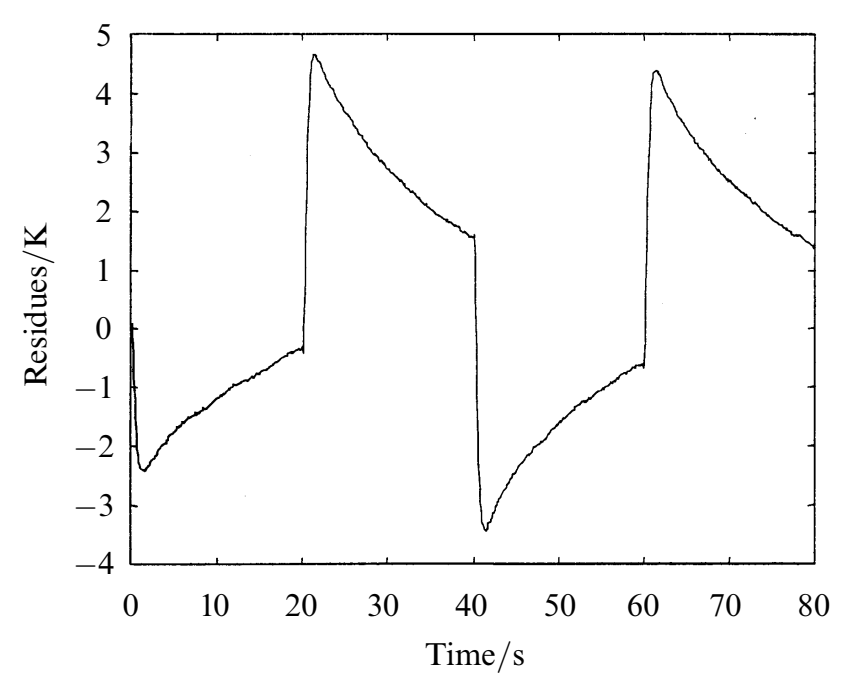

Figure 10. Computation of the residues $(\Delta t=0.1 \mathrm{~s})$.

To evaluate the bias of the method, the residues of estimation $\varepsilon(t)$ were computed (figure 10). This has revealed a large bias due to incorrect description of the thermal behaviour of the system in very brief time intervals. Asymptotic development of the transfer function $H(p)$, given by relation (4), to brief time intervals $(p \rightarrow \infty)$, allows the validity of the model to be evaluated:

$$
\theta(p) \simeq \frac{\beta_{2}}{\alpha_{3} p} \Phi(p) \simeq \frac{1}{\left(\rho C_{p}\right)_{\mathrm{s}} e_{\mathrm{s}} p} \Phi(p) .
$$

It is seen that here the transient effects of the probe are not properly taken into account. Consequently, we suggested that the model would be improved by adding a new parameter $\beta_{3}$ in relation (4):

$$
\left(\alpha_{1} p^{0.5}+\alpha_{2} p^{1}+\alpha_{3} p^{1.5}\right) \theta(p)=\left(\beta_{1} p^{0}+\beta_{2} p^{0.5}+\beta_{3} p^{1}\right) \Phi(p) .
$$

This allows better approximation of very fast effects in the probe:

$$
\underset{p \rightarrow \infty}{\theta(p)} \simeq \frac{\beta_{3}}{\alpha_{3} p^{0.5}} \Phi(p) \text {. }
$$

The new vector providing the estimate is $\boldsymbol{\vartheta}=\left[\begin{array}{lllll}\alpha_{2} & \alpha_{3} & \beta_{1} & \beta_{2} & \beta_{3}\end{array}\right]^{T}$. Parameter values calculated with the use of equation (14) are listed in table 2. Plot of the residues $\varepsilon(t)$ in figure 11 shows that our estimate is unbiased and therefore the parameters determined by us are not skewed. Using the differential model and parameters in table 2 we can now

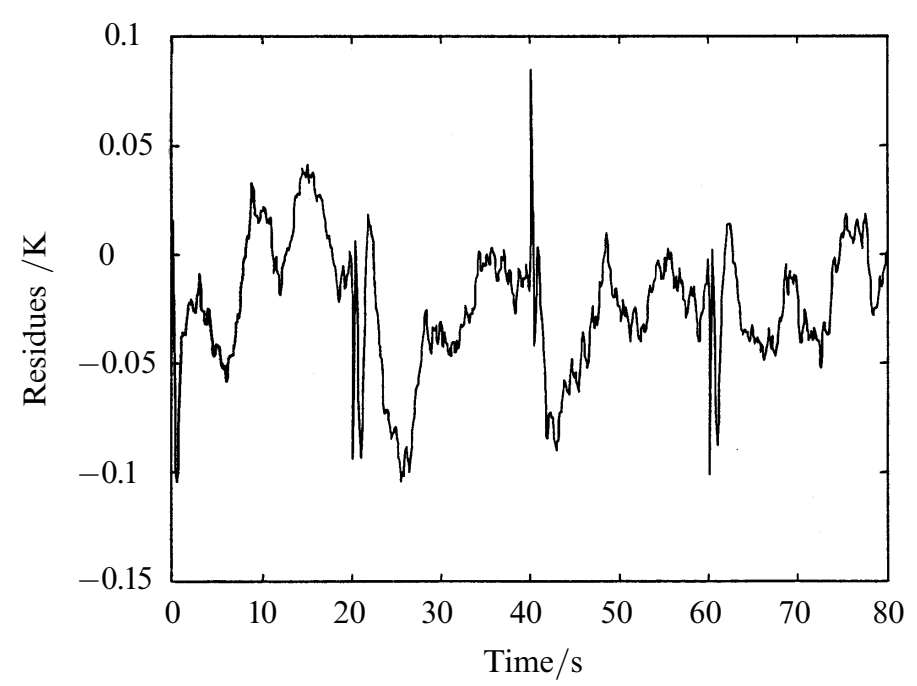

Figure 11. Computation of the residues $(\Delta t=0.1 \mathrm{~s})$. 
Table 2. Parameters determined from the response to the heat flux $(\Delta t=0.1 \mathrm{~s})$.

Derivative order Differential model parameters

$$
\begin{array}{ll}
\boldsymbol{n}_{\alpha}=\left[\begin{array}{c}
0.5 \\
1 \\
1.5
\end{array}\right] & \boldsymbol{\alpha}=\left[\begin{array}{c}
1 \\
-0.2003 \\
0.3204
\end{array}\right] \\
\boldsymbol{n}_{\beta}=\left[\begin{array}{c}
0 \\
0.5 \\
1
\end{array}\right] & \boldsymbol{\beta}=\left[\begin{array}{r}
2.82 \times 10^{-5} \\
3.98 \times 10^{-4} \\
-1.15 \times 10^{-4}
\end{array}\right]
\end{array}
$$

Table 3. Thermal properties determined from table 2.

\begin{tabular}{lll}
\hline & Determined values & Standard deviation \\
\hline $\begin{array}{l}\text { Thermal effusivity, } \\
\left(\lambda \rho C_{p}\right)^{1 / 2} / \mathrm{W} \mathrm{m}^{-2} \mathrm{~K}^{-1} \mathrm{~s}^{1 / 2}\end{array}$ & $36 \times 10^{3}$ & $6 \times 10^{3}$ \\
$\begin{array}{l}\text { Thermal resistance, } \\
R / \mathrm{m}^{2} \mathrm{~K} \mathrm{~W}^{-1}\end{array}$ & $40 \times 10^{-5}$ & $2 \times 10^{-5}$ \\
$\begin{array}{l}\text { Inertia probe, } \\
\left(\rho C_{p}\right)_{\mathrm{s}} e_{\mathrm{s}} / \mathrm{J} \mathrm{m}^{-2} \mathrm{~K}^{-1}\end{array}$ & 805 & 124 \\
\hline
\end{tabular}

calculate the thermal properties (see table 3). Thermal effusivity of the copper plate is found to be of the same order as found in the literature.

\section{Summary and conclusions}

A new simple method is reported for characterising thermally conductive thin plates in longitudinal direction. The experimental procedure is very simple with light and inexpensive devices used for the measurements. The behaviour of the physical system on application of a heat flux to the lateral surface is determined by using a non-integer model. Study of the sensitivity of the modulus and phase of the transfer function to the various parameters allows evaluation of the possibility of simultaneous determination of the parameters. The study also makes it possible to optimise the frequency window according to the required objectives and leads to a reduction of the model. This frequency treatment makes the method undemanding as regards limit conditions and, particularly, external thermal disturbances. The identification problem is solved by a linear least-squares technique, giving a robust and fast determination. Use of this method to estimate thermal effusivity of a semi-infinite copper plate was found to yield good results.

\section{References}

Battaglia J L, Le Lay L, Batsale J C, Oustaloup A, Cois O, 2000 Int. J. Thermal Sci. 39 $374-389$

Degiovanni A, Laurent M, 1986 Rev. Phys. Appl. 21 229-237

Degiovanni A, Lachi M, Batsale J C, 1990, in Comptes Rendus des Septièmes Journées Nationales sur Composites (Lyon: Association pour les Matériaux Composites, AMAC) pp 557-586

Hadisaroyo D, Batsale J C, Degiovanni A, 1992 J. Phys. III 2 111-128

Katayama K, Ohuchi K, Kotake S, 1969 Bull. Jpn. Soc. Mech. Eng. 52 865-872

Ljung L, 1987 System Identification. Theory for the User (Englewood Cliffs, NJ: Prentice-Hall)

Maillet D, André S, Batsale J C, Degiovanni A, Moyne C, 2000 Thermal Quadrupoles. Solving the Heat Equation through Integral Transforms (New York: John Wiley)

Miller K S, Ross B, 1993 An Introduction to the Fractional Calculus and Fractional Differential Equations (New York: John Wiley) 
Oustaloup A, 1995 La dérivation non entière: théorie, synthèse et applications (Paris: Hermès) Parker W J, Jenkins W, Butler C P, Abbot G L, 1961 J. Appl. Phys. 32 1679-1684

Philippi I, 1994 Mesure sans contact de diffusivité thermique de plaques minces en mouvement uniforme Thèse de doctorat INPL

Skumanich A, Dersch J, Fathallah M, Amer N M, 1987 Appl. Phys. A 43 297-300

Zhang X, Degiovanni A, 1993 J. Phys. III 3 1243-1265 